\title{
PENGARUH ABU TERBANG (FLY ASH) PLTU SEKAYAN SEBAgAI SUBTITUSI PENGGANTI SEBAGIAN SEMEN PADA JUAT TEKAN MORTAR
}

\section{EFFECT OF FLY ASH PLTU SEKAYAN AS A SUBSTITUTE FOR SOME OF THE CEMENT IN THE PRESS ON MORTAR}

\author{
Nofrisal ${ }^{1)}$, Sepry Rantesalu ${ }^{2)}$ \\ Program Studi Teknik Sipil, Fakultas Teknik, Universitas Kaltara \\ Tj. Selor, Kabupaten Bulungan, Kalimantan Utara 77216 \\ Email: ${ }^{1}$ nofrizal020481@gmail.com, ${ }^{2}$ sepry77@gmail.com
}

\begin{abstract}
ABSTRAK
Pemanfaatan Abu Terbang (fly ash) terhadap mortar memiliki tujuan jangka panjang yaitu mengurangi permasalahan limbah hasil pembakaran batu bara dan mengurangi pencemaran emisi gas rumah kaca dengan menurunkan pemakaian semen secara signifikan dalam pembuatan produk mortar. Selain mengatasi permasalahan limbah, penelitian ini juga diharapkan memberikan kemanfaatan pada beton, karena fly ash yang memiliki kadar silika $\left(\mathrm{SiO}_{2}\right)$ yang cukup tinggi telah terbukti memperbaiki sifat mekanis mortar sebagaimana studi pustaka yang telah ada. Penggunaan volume fly ash pada mortar adalah minimal $10 \%$ bahan pengikat/ semen digantikan oleh abu terbang sehingga secara signifikan meningkatkan pemakaian abu terbang. Dalam pembuatan mortar menggunakan cara yang identik dengan pembuatan mortar normal. Penelitian yang pernah dilakukan telah membuktikan bahwa penggunaan $50 \%$ fly ash sebagai pengganti semen pada mortar memenuhi standart mortar tipe $\mathrm{N}$ dengan perbandingan semen : pasir adalah $1: 6$ menghasilkan kuat tekan yang setara dengan mortar normal. Tujuan dari penelitian ini adalah untuk mengetahui pengaruh abu terbang (fly ash) PLTU Sekayan terhadap kuat tekan mortar optimum dengan jumlah variasi fly ash $10 \%, 15 \%, 25 \%$,dan $40 \%$. Ada 2 (dua) garis besar yang akan dilakukan dalam penelitian ini yang pertama yaitu melakukan pengujian sifat fisis terhadap agregat halus yang digunakan dalam campuran mortar sesuai dengan standar ASTM, yang kedua melakukan pengujian sifat mekanis yaitu uji kuat tekan benda uji mortar. Benda uji yang digunakan pada penelitian ini yaitu kubus,ukuran $5 \mathrm{~cm} \times 5 \mathrm{~cm} \times 5 \mathrm{~cm}$ yang jumlahnya 6 benda uji untuk masing-masing variasi untuk pengujian kuat tekan. Pengujian kuat tekan dilakukan pada umur 7 hari dan 28 hari. Metode yang digunakan pada campuran mortar sesuai dengan SNI 15-3758-2004,SNI 036882-2002 dan SNI 15-2049-2004. Dari hasil penelitian dapat disimpulkan bahwa kuat tekan mortar dengan fly ash $15 \%, 25 \%$ dan $40 \%$ lebih rendah bila dibandingkan dengan kuat tekan mortar tanpa fly ash pada umur 7 hari. Hal ini disebabkan karena perilaku fly ash dalam reaksi hidrasi berjalan lambat. Sedangkan pada umur 28 hari, kuat tekan mortar dengan fly ash $10 \%$ dan $15 \%$ lebih tinggi dibandingkan dengan mortar tanpa fly ash. Fenomena ini disebabkan oleh kapur bebas hasil reaksi semen dan air akan bereaksi dengan fly ash membentuk senyawa tobermorite.
\end{abstract}

Kata Kunci : Fly Ash; Limbah; Agregat; Mortar; Fisis; Mekanisme; Reaksi; Senyawa

\section{ABSTRACT}

Fly ash utilization for mortar has a long term purpose that reduces the problem of coal burning waste and reduces greenhouse gas emissions pollution by lowering cement consumption significantly in the manufacture of mortar products. In addition to addressing waste problems, this research is also expected to provide benefits to concrete, because the fly ash that has a high level of silica ( $\mathrm{SiO} 2$ ) is proven to improve the mechanical properties 
of mortar as well as existing library studies. The use of fly ash volume in mortar is at least $10 \%$ binder/cement replaced by fly ash so significantly increase the use of flying ash. In the manufacture of mortar use an identical way with normal mortar making. Research has been conducted has proved that the use of $50 \%$ fly ash as a substitute for cement in mortar meets the standard $\mathrm{N}$ mortar with a cement ratio: the sand is $1: 6$ producing a strong press that is equivalent to normal mortar. The purpose of this research is to know the influence of fly ash PLTU Sekayan against strong mortar press optimum with the number of fly ash variations $10 \%, 15 \%, 25 \%$, and $40 \%$. There are 2 (two) outlines that will be done in this study the first is to test the PHISYCS properties of the fine aggregate used in the mortar mixture in accordance with the ASTM standard, the second is to test the mechanical properties of a strong test of the mortar test objects. The test object used in this research is a cube, a size of $5 \mathrm{~cm} \times 5 \mathrm{~cm} \times 5 \mathrm{~cm}$ which amounts to 6 test objects for each variation for strong press testing. Strong press testing is done at 7 days and 28 days. The method used in mortar mixture in accordance with SNI 15-3758 -2004, SNI 03-6882-2002 and SNI 152049-2004. From the results of the study can be concluded that strong press mortar with fly ash $15 \%, 25 \%$ and $40 \%$ lower when compared with a strong press mortar without fly ash at the age of 7 days. This is due to the behavior of fly ash in a slow-running hydration reaction. While at the age of 28 days, strong press mortar with fly ash $10 \%$ and $15 \%$ higher than mortar without fly ash. This phenomenon is caused by the free lime reaction of cement and water will react with fly ash forming tobermorite compounds.

\section{Keywords: Fly Ash; Waste; Aggregate; Mortar; Phisycs; Mechanical; Reaction; Compound}

\section{PENDAHULUAN}

Pembangunan sektor industri di Indonesia terus meningkat sejalan dengan kemajuan ilmu pengetahuan dan teknologi. Meningkatnya sektor industri dapat mempernbaiki kualitas hidup dan pendapatan masyarakat, tetapi di sisi lain meningkatnya sektor industri dapat menurunkan kualitas lingkungan dan derajat kesehatan masyarakat. Akibat naiknya harga minyak diesel industri, salah satunya adalah maka banyak industri-industri yang beralih menggunakan batu bara sebagai bahan bakar dalam menghasilkan steam (uap) sebagai sumber energi produksi. Karena dinilai penggunaan batu bara sebagai bahan bakar akan mengurangi biaya produksi yang dikeluarkan oleh perusahaan.

Salah satu industri yang memilih menggunakan bahan bakar batu bara adalah PT. SAS (Sumber Alam Sekurau) yang terletak di desa Apung SP V Kecamatan Tanjung Selor Kabupaten Bulungan Provinsi Kalimantan Utara. PT.
SAS (Sumber Alam Sekurau) merupakan salah satu anak perusahaan dari PT. PKN (Pesona Katulistiwa Nusantara) yaitu perusahaan yang memiliki izin mengelola beberapa tambang batu batu bara yang ada di Provinsi Kalimantan Utara. PT. SAS bergerak dalam industri pembangkit listrik yaitu PLTU (Pembangkit Listrik Tenaga Uap) Sekayan. PLTU Sekayan milik PT. Sumber Alam Sekurau (SAS) ini memiliki power 2x7,5 Mega Watt (MW). Dari 7,5 MW daya yang dimiliki, 2 MW di antaranya akan disalurkan kepada masyarakat Kabupaten Bulungan melalui PLN selaku pihak teknis. Kemudian pemakaian daya akan dibebankan sesuai dengan peraturan Kepmen, sebesar 11,5 sen USD per $\mathrm{KWH}$, atau jika menggunakan diesel sekitar 30 sen USD per KWH. Sementara, sisanya akan digunakan untuk keperluan operasional perusahaan sendiri karena menggunakan energi listrik.

Selain dapat menghemat biaya operasional, ketersediaan batu bara cukup melimpah. Namun disisi lain pemanfaatan batu bara sebagai bahan bakar 
menimbulkan masalah baru yaitu limbah fly ash (abu terbang) dan bottom ash (abu dasar), diperkirakan jumlah fly ash yang dihasilkan oleh PLTU Sekayan mencapai 10 ton per hari. Jika masalah itu dibiarkan terus menerus dan tidak ada upaya pengelolaan limbah tersebut akan mengakibatkan pencemaran pada lingkungan.

Fly ash (abu terbang) adalah salah satu residu yang dihasilkan dalam pembakaran dan terdiri dari partikel-partikel halus. Abu yang tidak naik disebut bottom ash. Dalam dunia industri, fly ash biasanya mengacu pada abu yang dihasilkan selama pembakaran batu bara. Fly ash umumnya ditangkap oleh electrostatic precipitators atau peralatan filtrasi partikel lain sebelum gas buang mencapai cerobong asap batu bara pembangkit listrik, dan bersama-sama dengan bottom ash dihapus dari bagian bawah tungku dalam hal ini bersama-sama dikenal sebagian abu batu bara.

Menurut ACI Committee 226 dijelaskan bahwa, fly-ash mempunyai butiran yang cukup halus, yaitu lolos ayakan No. 325 (45 milimikron) $5-27 \%$, dengan spesific gravity antara 2,15-2,8 dan berwarn abuabu kehitaman. Sifat proses pozzolanic dari fly ash mirip dengan bahan pozzolan lainnya. Menurut ASTM C.618 (ASTM, 1995:304) abu terbang (fly-ash) didefinisikan sebagai butiran halus residu pembakaran batu bara atau bubuk batu bara. Fly-ash dapat dibedakan menjadi dua, yaitu abu terbang yang normal yang dihasilkan dari pembakaran batu bara antrasit atau batu bara bitomius dan abu terbang kelas $C$ yang dihasilkan dari batu bara jenis lignite atau subbitumes. Abu terbang kelas $C$ kemungkinan mengandung zat kimia $\mathrm{SiO} 2$ sampai dengan dengan $70 \%$.

Selama ini perlakuan fly ash yang ada di PLTU Sekayan sebagian besar ditimbunan pada galian-galian tanah. Abu terbang ini sendiri, kalau tidak dimanfaatkan juga bisa menjadi ancaman bagi lingkungan. Karenanya dapat dikatakan pemanfaatan abu terbang akan mendatangkan efek ganda pada tindak penyelamatan lingkungan, yaitu penggunaan abu terbang akan memangkas dampak negatif kalau bahan sisa ini dibuang begitu saja dan sekaligus mengurangi penggunaan semen Portland dalam pembuatan beton (Hardjito, 2001). Mortar dengan perbandingan semen : pasir adalah 1: 6 memenuhi standar kuat tekan mortar ( Agus Maryoto,2008). Penelitian tentang abu terbang (fly ash) untuk PLTU Sekayan belum pernah dilakukan, sehingga perlu dilakukan penelitian mengenai abu terbang (fly ash) untuk mortar. Yang diharapkan penelitian abu terbang (fly ash) untuk mortar ini bisa dinikmati masyrakat biasa untuk pembangunan rumah, jalan lingkungan masyarakat dan lain-lain.

\section{METODE PENELITIAN}

\section{a. Tahapan-Tahapan Penelitian}

Kuat tekan mortar adalah besarnya beban persatuan luas yang menyebabkan benda uji mortar hancur bila dibebani. Dalam pelaksanaan penelitian ini dilakukan beberapa tahap penelitian mulai dari pemilihan matrial mortar,pengujian matrial,pembuatan bena uji,pengujian benda uji,analisis data dan penarikan kesimpulan dari hasil penelitian.

Sebagai penelitian ilmiah,maka penelitian ini harus dilaksanakan dalam sistematika dan urutan yang jelas dant teratur sehingga nantinya diperoleh hasil yang memuaskan dan dapat dipertanggung jawabkan. Oleh Karena itu,pelaksanaan penelitian dibagi dalam bebarapa tahap, yaitu seperti pada gambar diagram alir penelitian berikut ini : 


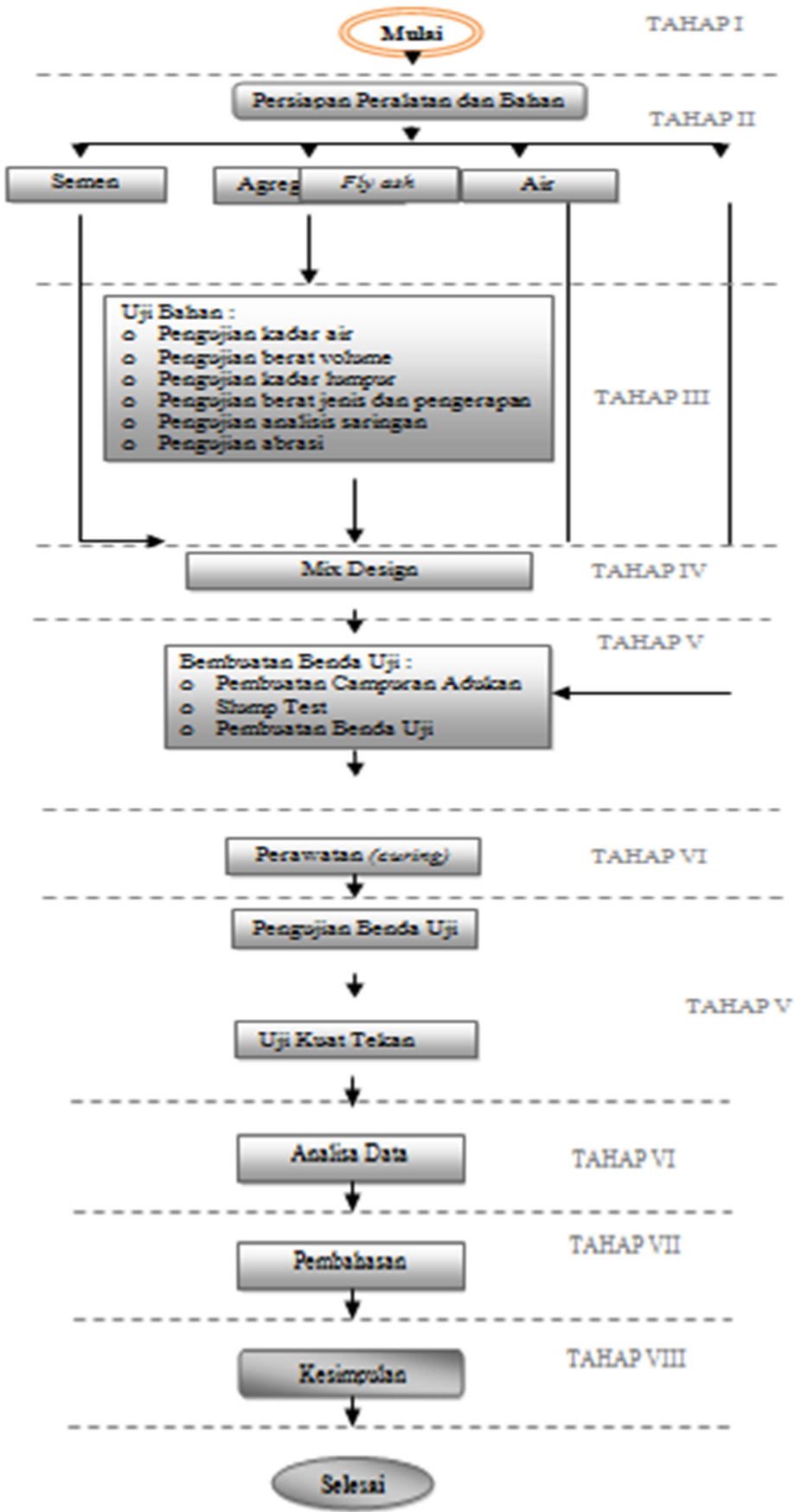

Gambar 1. Diagram Alir Metode Penelitian

\section{b. Lokasi Penelitian}

Penelitian sifat fisis material dan sifat mekanis benda uji mortar dilakukan di Laboratorium Bahan Dinas Pekerjaan Umum Kabupaten Bulungan.

\section{c. Peubah Yang Diamati atau Diukur}

Dilakukan pada material penyusun mortar. Pengujian ini dimaksudkan untuk mengetahui sifat dan karakteristik dari material pembentuk mortar. Pengujian dilakukan sesuai dengan standar yangada.Dalam penelitian ini hanya dilakukan pengujian terhadap agregat halus,sedangkan terhadap semen tidak dilakukan pengujian. Bahan dan tahapan pemeriksaan meliputi:

1) Pemeriksaan semen

Semen diperiksa dengan mengamati secara visual kemasan kantong atau 
zak dalam keadaan tertutup rapat, bahan butiran halus tidak menggumpal.

2) Pemeriksaan air

Air diperiksa warna dan kejernihannya secara visual.

3) Pemeriksaan Agregat

Agregat adalah butiran mineral alami yang berfungsi sebagai bahan campuran mortar,agregat yang digunakan pada campuran mortar adalah agregat halus. Pemeriksaan agregat halus meliputi : kadar air,berat volume, kadar lumpur, berat jenis dan penyerapan, analisa saringan.

\section{d. Perencanaan Campuran (Mix Design)}

Rencana campuran mortar antara semen, air dan agregat-agregat sangat penting untuk mendapatkan kekuatan mortar mutu yangsesuai dengan yang diharapkan. Perancangan campuran adukan mortar yang bertujuan untuk memperoleh kualitas mortar normal. Dalam penelitian ini rencana campuran mortar menggunakan SNI 03-6825-2002 "Metode Pengujian Kekuatan Tekan Mortar Semen Portland Untuk Pekerjaan Sipil ".Besarnya persentase pergantian semen dengan fly ash pada setiap benda uji adalah $0 \%$, $10 \%, 15 \%$, 25\%,dan $40 \%$.

\section{e. Pembuatan Benda Uji}

Pembuatan benda uji mulai dari tahap pembuatan campuran hingga pencetakan benda uji. Benda uji kubus dengan sisi $5 \mathrm{~cm}$ dibuat sebanyak 30 buah untuk pengujian umur 7 hari dan 30 buah untuk pengujian umur 28 hari.

\section{f. Perawatan Benda Uji}

Pembuatan benda uji mulai dari tahap pembuatan campuran hingga pencetakan benda uji. Benda uji kubus dengan sisi $5 \mathrm{~cm}$ dibuat sebanyak 30 buah untuk pengujian umur 7 hari dan 30 buah untuk pengujian umur 28 hari.

\section{g. Menghitung Berat Volume Mortar}

Nilai ini menyatakan berat mortar persatuan volume yang dapat dirumuskan sebagai :

$$
\mathrm{BV}=\frac{\mathrm{Bs}}{\mathrm{Vb}}
$$

$$
\text { Keterangan : } \begin{aligned}
\mathrm{BV} & =\text { Berat volume mortar }(\mathrm{kg} / \mathrm{cm} 3) \\
\mathrm{B}_{\mathrm{s}} & =\text { Berat mortar }(\mathrm{kg}) \\
\mathrm{V}_{\mathrm{b}} & =\text { Volume mortar }(\mathrm{cm})
\end{aligned}
$$

\section{h. Pengujian Kuat Tekan Mortar}

Pengujian kuat tekan mortar yang dilakukan pada umur mortar 7 hari dan 28 hari, langkah-langkah pengujiannya adalah

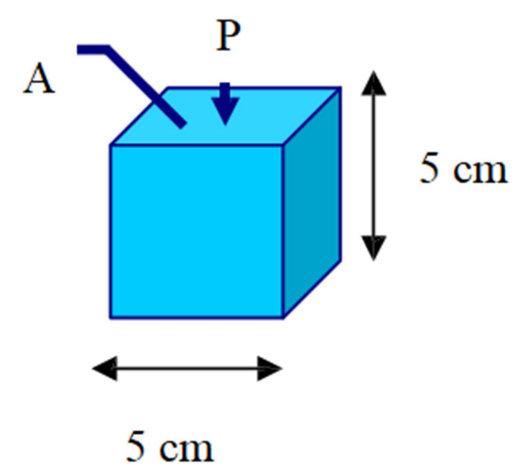

\section{Gambar 2. Uji Kuat Tekan}

Perhitungan kuat tekan mortar diperoleh berdasarkan rumus :

$f^{\prime} m=\frac{P}{A}$

Keterangan :

$f^{\prime} m=$ kuat tekan mortar, dalam $\mathrm{kg} / \mathrm{cm}^{2}$

$P \quad=$ beban maksimum total, dalam $\mathrm{kg}$

$A=$ luas dari permukaan yang dibebani, dalam $\mathrm{cm}^{2}$

\section{i. Teknik Pengumpulan Dan} Analisa Data

Setelah bahan dan alat uji siap serta sampel uji telah dibuat, maka siap untuk diuji sesuai prosedur penelitian. Hasil dari pengujian berupa data sementara yang masih perlu diolah lebih lanjut untuk mengetahui hubungan/korelasi antara satu pengujian dengan pengujian lainnya. Secara umum dari pengujian-pengujian yang akan dilakukan nantinya akan menghasilkan pengaruh perawatan dan penambahan additif pada mutu mortar. 
JURNAL BORNEO SAINTEK

Volume 3, Nomor 1, April 2020

e-ISSN 2599-3313

p-ISSN 2615-434X

Setelah itu dilakukan pembahasan terhadap yang diperoleh dari penelitian tersebut untuk kemudian ditarik menjadi suatu kesimpulan.
Available online at www.jurnal.borneo.ac.id Halaman 19-27

\section{HASIL DAN PEMBAHASAN}

Hasil pengujian sifat fisis terhadap agregat halus yang digunakan dalam campuran mortar sesuai dengan standar ASTM adalah sebagai berikut:

Tabel 1. Hasil Uji Sifat Fisis Agregat Halus

\begin{tabular}{|l|l|l|l|l|}
\hline No & JenisPengujian & Hasil Pengujian & Syarat & Keterangan \\
\hline 1 & Specific Grafity & 2,53 & $2,5-2,7$ & Memenuhi Syarat \\
\hline 2 & Absorbtion & $3,03 \quad(\%)$ & - & - \\
\hline 3 & Unit weight & $1,31 \quad\left(\mathrm{gr} / \mathrm{cm}^{3}\right)$ & - & - \\
\hline 4 & Material Content & $2,67 \quad(\%)$ & Max 5\% & Memenuhi Syarat \\
\hline 5 & Water Content & $1,73 \quad(\%)$ & - & - \\
\hline 6 & Fineness Modulus & $3,00 \quad(\%)$ & $2,3-3,1$ & Memenuhi Syarat \\
\hline 7 & Organic Impurity & Coklat & & \\
\hline
\end{tabular}

Untuk rancangan campuran mortar adalah sebagai berikut :

Dalam penelitian ini, komposisi campuran mortar menggunakan metode perbandingan berat antara semen dan pasir yaitu 1 : 4, sedangkan untuk volume air dilakukan beberapa kali percobaan untuk mendapat nilai slump mortar $110 \pm 5$, dan didapatkan nilai slump $11,2 \mathrm{~cm}$ dengan volume air 120 ml untuk $180 \mathrm{gr}$ semen dan $720 \mathrm{gr}$ pasir untuk mortar kubus $5 \times 5$ sebanyak 3 buah.

Untuk Berat volume volume mortar dapat dicari setelah dilakukan pengujian berat kubus mortar dengan menggunakan timbangan elektrik. Hasil perhitungan berat volume rata-rata tiap kubus mortar dengan sisi $5 \mathrm{~cm}$ proporsi campuran pada umur 7 hari dan 28 Hari dapat dilihat pada Tabel 2 dibawah ini :

Tabel 2. Berat Volume Mortar Normal

\begin{tabular}{|c|l|l|}
\hline BENDA UJI & \multicolumn{2}{|c|}{ BERAT VOLUME MORTAR (Kg/ $\left.\mathbf{~}^{\mathbf{3}}\right)$} \\
\hline UMUR (HARI) & \multicolumn{1}{|c|}{$\mathbf{7}$ hari $\mathbf{~ h a r i}$} \\
\hline MORTAR F.A 0 \% & $1.982,4$ & $1.929,6$ \\
\hline & $1.984,8$ & $1.938,4$ \\
\hline & $1.994,4$ & $1.944,8$ \\
\hline & $1.996,0$ & $1.946,4$ \\
\hline & $1.976,8$ & $1.932,0$ \\
\hline & $1.974,4$ & $1.872,8$ \\
\hline Hasil Analisa & $1.984,8$ & $1.927,3$ \\
\hline MORTAR F.A 10 \% & $1.969,6$ & $1.930,4$ \\
\hline & $1.978,4$ & $1.931,2$ \\
\hline & $1.972,8$ & $1.925,6$ \\
\hline & $1.965,6$ & $1.914,4$ \\
\hline & $1.959,2$ & $1.909,6$ \\
\hline & $1.976,8$ & $1.955,2$ \\
\hline & $1.970,4$ & $1.927,7$ \\
\hline Hasil Analisa & $1.968,8$ & $1.921,6$ \\
\hline MORTAR F.A 15 \% & $1.991,2$ & $1.940,8$ \\
\hline & $1.971,2$ & $1.923,2$ \\
\hline & $1.964,0$ & $1.907,2$ \\
\hline & & \\
\hline
\end{tabular}




\begin{tabular}{|c|c|c|}
\hline & $1.968,0$ & $1.909,6$ \\
\hline & $1.959,2$ & $1.905,6$ \\
\hline Hasil Analisa & $1.969,7$ & $1.918,0$ \\
\hline \multirow[t]{6}{*}{ MORTAR F.A $25 \%$} & $1.928,8$ & $1.884,0$ \\
\hline & $1.965,6$ & $1.950,4$ \\
\hline & $1.992,0$ & $1.891,2$ \\
\hline & $1.970,4$ & $1.888,8$ \\
\hline & $1.944,8$ & $1.859,2$ \\
\hline & $1.940,0$ & $1.853,6$ \\
\hline \multirow{7}{*}{$\begin{array}{l}\text { Hasil Analisa } \\
\text { MORTAR F.A } 40 \%\end{array}$} & $1.956,9$ & $1.887,9$ \\
\hline & $1.920,8$ & $1.831,2$ \\
\hline & $1.916,8$ & $1.857,6$ \\
\hline & $1.938,4$ & $1.841,6$ \\
\hline & $1.932,0$ & $1.854,4$ \\
\hline & $1.926,4$ & $1.802,4$ \\
\hline & $1.936,8$ & $1.840,8$ \\
\hline Hasil Analisa & $1.928,5$ & $1.838,0$ \\
\hline
\end{tabular}

Hasil pengujian kuat tekan mortar yang terbang) dapat dilihat pada Tabel 3 menggunakan bahan tambah fly ash (abu berikut :

Tabel 3. Berat Volume Mortar Fly Ash

\begin{tabular}{|c|c|c|}
\hline BENDA UJI & \multicolumn{2}{|c|}{ KUAT TEKAN $\left(\mathrm{Kg} / \mathrm{Cm}^{2}\right)$} \\
\hline UMUR (HARI) & 7 hari & 28 hari \\
\hline \multirow[t]{6}{*}{ MORTAR F.A $0 \%$} & 57,48 & 73,65 \\
\hline & 61,07 & 72,30 \\
\hline & 57,48 & 70,95 \\
\hline & 61,07 & 74,54 \\
\hline & 58,38 & 70,50 \\
\hline & 60,17 & 72,75 \\
\hline Hasil Analisa & 56,47 & 69,90 \\
\hline \multirow[t]{6}{*}{ MORTAR F.A $10 \%$} & 59,28 & 77,24 \\
\hline & 62,87 & 73,65 \\
\hline & 60,17 & 76,34 \\
\hline & 59,28 & 74,54 \\
\hline & 62,87 & 78,14 \\
\hline & 63,77 & 74,54 \\
\hline Hasil Analisa & 58,05 & 72,84 \\
\hline \multirow[t]{6}{*}{ MORTAR F.A $15 \%$} & 46,70 & 77,24 \\
\hline & 51,19 & 78,14 \\
\hline & 49,40 & 79,93 \\
\hline & 50,29 & 75,44 \\
\hline & 48,50 & 79,03 \\
\hline & 47,60 & 81,73 \\
\hline
\end{tabular}




\begin{tabular}{|l|l|l|}
\hline Hasil Analisa & $\mathbf{4 6 , 1 8}$ & $\mathbf{7 5 , 0 0}$ \\
\hline MORTAR F.A 25 \% & 44,01 & 61,07 \\
\hline & 45,80 & 58,38 \\
\hline & 43,11 & 59,28 \\
\hline & 42,21 & 60,17 \\
\hline & 44,91 & 61,07 \\
\hline Hasil Analisa & 43,11 & 57,48 \\
\hline MORTAR F.A 40 \% & $\mathbf{4 1 , 6 8}$ & $\mathbf{5 7 , 1 6}$ \\
\hline & 26,05 & 57,48 \\
\hline & 24,25 & 56,58 \\
\hline & 23,35 & 58,38 \\
\hline & 25,15 & 55,68 \\
\hline & 24,25 & 53,89 \\
\hline Hasil Analisa & 26,05 & 52,09 \\
\hline & $\mathbf{2 3 , 0 6}$ & $\mathbf{5 1 , 8 3}$ \\
\hline
\end{tabular}

Adapun hubungan nilai kuat tekan dengan umur mortar dapat digambarkan dalam grafik sebagai berikut :

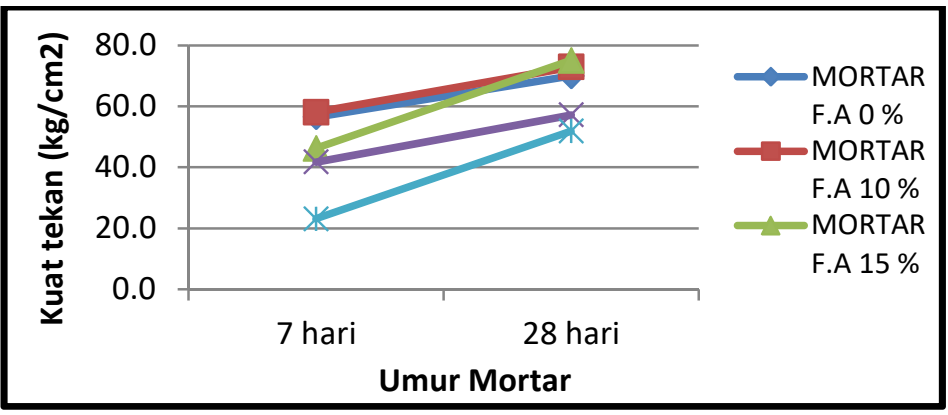

\section{Gambar 3. Grafik Hubungan Nilai Kuat Tekan Dengan Umur Mortar}

Dari hasil penelitian (lihat grafik) terlihat bahwa kuat tekan mortar dengan fly ash $15 \%, 25 \%$ dan $40 \%$ lebih rendah bila dibandingkan dengan kuat tekan mortar tanpa fly ash pada umur 7 hari. Hal ini disebabkan karena perilaku fly ash dalam reaksi hidrasi berjalan lambat. Sedangkan pada umur 28 hari, kuat tekan mortar dengan fly ash $10 \%$ dan $15 \%$ lebih tinggi dibandingkan dengan mortar tanpa fly ash. Fenomena ini disebabkan oleh kapur bebas hasil reaksi semen dan air akan bereaksi dengan fly ash membentuk senyawa tobermorite. Reaksi fly ash dan kapur bebas disebutkan dalam Tjokrodimuljo (1996) sebagai berikut :
$3 \mathrm{Ca}(\mathrm{OH}) 2+2 \mathrm{SiO}_{2}+3 \mathrm{H}_{2} \mathrm{O} \rightarrow 3 \mathrm{CaO}-2 \mathrm{SiO}_{2}-$ $3 \mathrm{H}_{2} \mathrm{O}$ atau $\left(\mathrm{C}_{3} \mathrm{~S}_{2} \mathrm{H}_{3}\right)$

Dan $\mathrm{Ca}(\mathrm{OH}) 2+\mathrm{Al} 2 \mathrm{O} 3+\mathrm{H} 2 \mathrm{O} \rightarrow 3 \mathrm{CaO}-$ $\mathrm{Al} 2 \mathrm{O} 3-6 \mathrm{H} 2 \mathrm{O}$ atau $\mathrm{C} 3 \mathrm{AH} 6$

Sementara reaksi yang terjadi pada semen adalah sebagai berikut:

$2 \mathrm{C} 3 \mathrm{~S}+6 \mathrm{H} 2 \mathrm{O} \rightarrow(\mathrm{C} 3 \mathrm{~S} 2 \mathrm{H} 3)+3 \mathrm{Ca}(\mathrm{OH}) 2$

$2 \mathrm{C} 2 \mathrm{~S}+4 \mathrm{H} 2 \mathrm{O} \rightarrow(\mathrm{C} 3 \mathrm{~S} 2 \mathrm{H} 3)+\mathrm{Ca}(\mathrm{OH}) 2$

$\mathrm{C} 3 \mathrm{~A}+6 \mathrm{H} 2 \mathrm{O} \rightarrow \mathrm{C} 3 \mathrm{AH} 6$

dimana : $\mathrm{C}=\mathrm{CaO} ; \mathrm{S}=\mathrm{SiO} 2 ; \mathrm{A}=\mathrm{Al} 2 \mathrm{O} 3$

\section{KESIMPULAN}

Pada penelitian Pemanfaatan Pengaruh fly ash (abu terbang) PLTU Sekayan pada mortar yang telah dilaksanakan, dapat 
diambil beberapa kesimpulan sebagai berikut :

1. Berat volume mortar normal proporsi 1Pc: 4Ps pada umur 7 hari sebanyak1.984,8 kg/m ${ }^{3}$, menurun pada kondisi optimum $40 \%$ fly ash sebesar2,83\% yaitu1.928,5 kg/m 3 . Berat volume mortar normal proporsi 1Pc: 4Ps pada umur 28 hari sebanyak $1927,3 \mathrm{~kg} / \mathrm{m}^{3}$, menurun pada kondisi optimum $40 \%$ fly ash sebesar $4.65 \%$ yaitu $1838,0 \mathrm{~kg} / \mathrm{m}^{3}$. Nilai kuat tekan optimum mortar umur 7 hari pada proporsi 1Pc:4Ps menggunakan abu terbang (fly ash) sebagai substitusi semen sebanyak $10 \%$ sebesar 58,05 $\mathrm{kg} / \mathrm{m}^{2}$ meningkat $2,79 \%$ dari mortar normal yang besarnya $56,47 \mathrm{~kg} / \mathrm{m}^{2}$ sedangkan nilai kuat tekan optimum mortar umur 28 hari pada proporsi 1Pc:4Ps menggunakan abu terbang (fly ash) sebagai substitusi semen sebanyak $15 \%$ sebesar $75,00 \mathrm{~kg} / \mathrm{m}^{2}$ meningkat $7,29 \%$ dari mortar normal yang besarnya $69,90 \mathrm{~kg} / \mathrm{m}^{2}$.

2. Pemanfaatan di bidang struktural

Pada kuat tekan proporsi 1Pc:4Ps dengan kandungan fly ash $10 \%$ dan $15 \%$ masuk dalam persyaratan mortar tipe $\mathrm{N}$ yaitu minimal $63 \mathrm{~kg} / \mathrm{m}^{2}$ sesuai SNI 15-3758-2004. Pada kuat tekan proporsi 1Pc:4Ps dengan kandungan fly ash (abu terbang) $10 \%$ dan $15 \%$ dapat di terapkan pada pembuatan bata beton berlubang karena masuk dalam persyaratan batako mutu II yaitu sebesar 67 $\mathrm{kg} / \mathrm{cm}^{2}$ dan Pada kuat tekan optimum proporsi 1Pc:4Ps kandungan fly ash (abu terbang) $25 \%$ dan $40 \%$ masuk dalam persyaratan batako mutu III yaitu $37 \mathrm{~kg} / \mathrm{cm}^{2}$, sesuai dengan syarat ketentuan SK SNI S04-1989-F.

\section{UCAPAN TERIMAKASIH}

Kepada Direktorat Riset Dan Pengabdian Masyarakat (Kemenristekdikti) Republik Indonesia Atas Dana Hibah Penelitian Dosen Pemula (PDP) Sehingga Berhasil Dengan Baik Dan Bermanfaat Bagi Masyarakat. Juga kepada tenaga lab. Bahan PUPR yang senantiasa bekerjasama dalam pelaksanaan penelitian ini.

\section{DAFTAR PUSTAKA}

Anonim, SNI-03-6825-2002, Metode Pengujian Kekuatan Tekan Mortar Semen, Badan Standar Nasional, Jakarta.

Anonim,SNI-03-6882-2002, Mortar untuk pasangan, Badan Standar Nasional, Jakarta.

Anonim, SNI 15-3758-2004, Semen masonry, Badan Standar Nasional, Jakarta.

Erlambang, 1997, Karakteristik Beton dengan Bahan Tambah Abu Terbang, Jurnal Yogyakarta.

Maryoto, 2003, Mix Design Mortar, PT. JayaReadymix, Semarang.

Wenno, 2014, Kuat tekan mortar dengan menggunakan abu terbang (fly ash) sebagai asal PLTU Amurang sebagai subtitusi parsial semen, Purwokerto.

Witarso, 2015, Pengaruh Penambahan Abu Terbang Pada Paving Block Berbahan Baku Tailing Asbuton, Jurnal Jalan Jembatan, Bandung.

Yatti, 1993, Penelitian Mutu Beton Abu Terbang pada Lingkungan yang Agresif (Pantai dan Laut), Jurnal Permukiman, Jakarta.

Agus Maryoto, 2008,Pengaruh Penggunaan High Volume Fly Ash Pada Kuat Tekan Mortar. 
